\title{
Numerical Accuracy of the Kiva4 Code under Different Ignition Timing on the Combustion Characteristics of Gasoline in a Spark Ignition Engine
}

\author{
Joseph Lungu, Lennox Siwale, Edwin Luwaya \\ Mechanical Department, Copperbelt University, Kitwe, Zambia \\ Email: josephlungu8512@gmail.com
}

How to cite this paper: Lungu, J., Siwale, L. and Luwaya, E. (2018) Numerical Accuracy of the Kiva4 Code under Different Ignition Timing on the Combustion Characteristics of Gasoline in a Spark Ignition Engine. Journal of Power and Energy Engineering, 6, 87-110.

https://doi.org/10.4236/jpee.2018.611008

Received: September 28, 2018

Accepted: November 25, 2018

Published: November 28, 2018

Copyright (๑) 2018 by authors and Scientific Research Publishing Inc. This work is licensed under the Creative Commons Attribution International License (CC BY 4.0).

http://creativecommons.org/licenses/by/4.0/

\begin{abstract}
The purpose of this work was to show that kiva4 is more accurate than kiva3vr2 under different ignition timings. The numerical accuracy of kiva4 was compared with the numerical results obtained by other researchers who used kiva3vr2 as the simulation code. The combustion characteristics of gasoline under different ignition timings are obtained using the kiva4 code. For achieving this, two cases were investigated; a complete engine cycle was successfully simulated using a four-valve pent-roof engine and a comparison was made with experimental results by other researchers. At a constant speed of 600 rpm, a BASF (Badische Anilin-und Soda Fabrik) octane rating engine-single cylinder was used where ignition timing was changed in the range of $4^{\circ}$ BTDC to $18^{\circ}$ BTDC. Kiva4 generates more accurate results than kiva3vr2. The experimental results were more in agreement with kiva4 than kiva3vr2 results. The average temperature and pressure in kiva4 were $640 \mathrm{~K}$ and 16.48 bars while in kiva3vr2 were $600 \mathrm{~K}$ and 14.83 bars, the peak temperature and pressure in kiva4 were $2316.3 \mathrm{~K}$ and 21.5 bars while in kiva3vr2 were $2171.5 \mathrm{~K}$ and 19.4 bars. The peak temperature and pressure increase with increasing spark advance until the most favorable instant time is determined. Best performance was achieved when the ignition time was set to 10 degrees before top dead center.
\end{abstract}

\section{Keywords}

Combustion, Kiva4, Accuracy, Ignition Timing, Gasoline

\section{Introduction}

Internal combustion engines have been in use for more than a century and have 
undergone tremendous changes in design and performance. In the past decades, research efforts have been focused largely on a better spark ignition engine, from the perspective of reducing the pollutant emissions without sacrificing performance and fuel economy.

Simulations based on the KIVA-3 code are widely used to predict diesel combustion. Several advanced sub-models have been developed using the KIVA-3 based code. However the numeric in Kiva4 has been generalized to unstructured mesh and it has the potential to enhance mesh structure flexibility while Kiva3vr2 has low mesh flexibility because of employing a structured mesh [1] [2]. In a structured mesh used in kiva3vr2, a regular connectivity is maintained using a 2D/3D array with only quadrilateral elements for $2 \mathrm{D}$ structures and hexahedral elements for a 3D structure. Unlike this, the unstructured meshes don't have a regular connectivity but any type of elements can be used to define the grid that includes prisms, pyramids, tetrahedral, etc. Though the neighborhood connectivity has to be explicitly stored consuming more storage, handling complex geometry will be a lot simpler. But the unstructured mesh has added some limitations on the snapping procedure and also requires changes in the Lagrangian phase of computation in the ALE methodology. These modifications lead to a few changes in the calculation of pressure solutions and the momentum fluxing [3]. One of the possible problems of the KIVA-3 type mesh is that it is limited only to use a polar mesh when the simulation model applies to a sector to reduce the computational time compared to a full circle mesh. The cell size of a polar mesh varies with location in the radial direction. If a finer mesh is applied in order to improve the resolution around the periphery of the piston bowl, the cell size near the cylinder axis becomes smaller and thinner. Since cells in this region contain a lot of droplets during the injection and combustion events, too small and thin cells lead to long CPU times for the gas phase calculation and can become a possible cause of prediction inaccuracy [1] [4]. The advantage of the unstructured mesh is that the code structure of KIVA-4 is different from Kiva3vr2 in order to facilitate the handling of unstructured mesh. The major changes in variables, are that the indexing of different components of the mesh becomes more specific in terms of addressing. In the previous versions, there was only node indexing used for defining all the components of the mesh like the cells, faces, etc., but in KIVA-4, every component has their unique address like cell indices, node indices, edge indices, face indices, etc. This component specific indexing helps keep the code in a more structured and organized way. Also, it is easier to access the properties of vertex or cell or face without much hassle. This also makes the code debugging easier, but the downside is that it requires more number of arrays/-variables than the previous versions. The other advantage is that the element types and face boundary types in Kiva- 4 are classified in a more detailed way than in Kiva3vr2. Table 1 indicates the element types. In KIVA-4, element types are available for every element of the mesh like for cells, nodes, faces, edges. For example in KIVA-3V, in order to find the 
Table 1. Node types [3].

\begin{tabular}{cc}
\hline Kiva 4 & Kiva3vr2 \\
squishnodes $=2$ & flfluid $=1.0$ \\
domenodes $=3$ & flface $=2.0$ \\
bowlnodes $=5$ & flbowl $=3.0$ \\
topbowlnodes $=7$ & flsqsh $=4.0$ \\
portnodes $=11$ & fldome $=5.0$ \\
axisnodes $=37$ & flhead $=6.0$ \\
inoutflownodes $=41$ & \\
presnodes $=43$ & \\
movingnodes $=47$ & \\
movingnodesvalve $=53$ & \\
solidnodes $=59$ & \\
solidhnodes $=61$ & \\
solidbnodes $=67$ &
\end{tabular}

length of all the 12 edges of a cell, all the nodes are identified first and then the distance nodes on various combination have to determined using the $x, y, z$ co-ordinates and this procedure has to be repeated every time length of the edge which is required. But in KIVA-4, the edges associated with each cell are stored in an array and the length of those edges can also be retrieved from the array directly [3] [5].

Although KIVA-4 still includes the i1tab, i3tab and i8tab bookkeeping arrays, the algorithm below clearly shows that KIVA-4 has a new approach to locate a node of the fluid (gird) cell. It is important to know that, for each computational cell, KIVA-4 no longer uses left, bottom, and front faces for surface area and outward normal vector identification. Table 2 indicates a sample code which illustrates the difference in code logic between the Kiva4 and Kiva3vr2 [3].

In recent years, however, ignition timing has also brought increased attention to the development of advanced SI engines for maximizing performance. The performance of spark ignition engines is a function of many factors. One of the most important ones is ignition timing. Also it is one of the most important parameters for optimizing efficiency and emissions, permitting combustion engines to conform to future emission targets and standards [6]. Ignition timing, in a spark ignition engine, is the process of setting the time that an ignition will occur in the combustion chamber (during the compression stroke) relative to piston position and crankshaft angular velocity. Produce and deliver a high-voltage spark from a low voltage supply source (the battery) [7]. This spark must be distributed to each combustion chamber as the piston nears top dead center on the compression stroke of the piston. Control and even alter when the spark occurs in the cylinder to meet different engine demands. Deliver a spark 
Table 2. Sample code [3].

\begin{tabular}{cc}
\hline Kiva4 & Kiva3vr2 \\
\hline do i4c $=1$, ncellsa & do i4 $=$ ifirst, ncells \\
$\mathrm{i} 1=\operatorname{nodes}(1, \mathrm{i} 4 \mathrm{c})$ & $\mathrm{i} 1=\mathrm{i} 1 \mathrm{tab}(\mathrm{i} 4)$ \\
$\mathrm{i} 3=\operatorname{nodes}(3, \mathrm{i} 4 \mathrm{c})$ & $\mathrm{i} 3=\mathrm{i} 3 \mathrm{tab}(\mathrm{i} 4)$ \\
Enddo & Enddo \\
\hline
\end{tabular}

that has enough voltage and energy to ensure combustion of the fuel mixture. Be able to reliably accomplish these goals throughout a variety of rpm, load, temperatures and conditions [7].

Optimization of the engine design and operating variables requires extensive engine testing. Therefore, engine modeling codes are generally preferred for assessing initial designs. Computer models of engine processes are useful tools for analysis and optimization of engine performance and allow exploration of many engine design alternatives in an inexpensive method [4]. The Kiva4 code is one example of computer models used, an advanced computational fluid dynamics (CFD) modeling code that accurately simulates the in-cylinder processes of engines. The objective of this study is to show that simulations done with Kiva4 give more accurate results than with Kiva3vr2 under different ignition timings. Others in ref. [2] [3] [5], have shown the accuracy of unstructured mesh with Kiva4 in comparison with structured mesh of Kiva3V, in this study further verification of the accuracy of simulations with Kiva4 in spark ignition engines is presented. Engine experiments conducted by others ref. [8], were used to compare results obtained in simulations between Kiva4 and Kiva3vr2. In addition, this work is the precursor to the subsequent studies which will predict the combustion characteristics of blends of gasoline with selected proven mix ratios of n-butanol and methanol blends. These oxygenated fuels have been used previously ref. [8] as additives to gasoline in order to reduce emissions.

\section{Previous Work}

The use of statistical techniques based on experimental data to evaluate the behavior of engines and fuels has been increasing in recent years. For example Christopher J. Rutland et al. Studied Effect of mesh structure in the KIVA4 code with a less mesh dependent spray model for DI diesel engine simulations, the predicted heat release rate using the gas-jet model showed good mesh independency and good agreement with the experiment while that using the standard KIVA spray model calculated with KIVA-4 show significant mesh dependency [2]. David J. Torres and Peter J. 0'Rourke studied Unstructured KIVA, Where a comparison was made between KIVA4 and KIVA3V in terms of indexing changes, timing comparison and limitations. The results showed that KIVA4 like KIVA3V assumes cells are logical hexahedra and in KIVA4 edges and/or faces can degenerate into points which allows for the use of prisms, tetrahedra, and pyramids. KIVA4 spends a larger amount of time in the momentum fluxing, 
velocity solver, and mass fraction solver than does KIVA3V [5]. A.H. Kakaee et al. Studied Sensitivity and Effect of Ignition Timing on the Performance of a Spark Ignition Engine, results showed that optimal power and torque are achieved at $31^{\circ} \mathrm{CA}$ before top dead center, and performance is decreased if this ignition timing is changed [6]. Tunka et al. Studied Effect of various ignition timings on combustion process and performance of gasoline engine, the measurement results showed that as the ignition timing increases, the engine power and torque also increase. The increase in these parameters is a reflection of higher pressure in the cylinder, the maximum value of which is achieved at higher ignition timing near the top dead centre in an expansion stroke.

\section{Methods and Materials}

\subsection{Materials}

The fuel used in both cases is gasoline and it was manufactured by MOL specification EN-95.The in-cylinder pressure was measured by a piezo-electric pressure transducer of the Type: Kistler 600. Top Dead Center (TDC) and engine piston speed, RPM, was determined by an optical encoder Type: Hengstler RI 32-0/1024.ER.14K. Fuel flow rate was measured using the AVL 7030 Dynamic fuel consumption measuring equipment. The fuel balance works on the gravimetric measuring principle. Fuel is supplied to the engine from a measuring vessel inside the instrument where the weight of the fuel is continuously measured. This instrument enables the highest temperature stability of the fuel conditioning system with measuring accuracy of $0.12 \%$; including self-calibration according to ISO $9001[8]$.

\subsection{Methods}

Two different cases were investigated, in both cases kiva4 and kiva3vr2 were compared in order to show the numerical accuracy of the kiva4 code.

Case A: From ref. [9], the engine used was a four valve pent-roof engine as indicted in Table 3.

Case B: Siwale et al. Performed experiments on a BASF (BadischeAnilin-und Soda Fabrik) octane rating single cylinder engine. The engine performance parameters are indicted in Table 4.

The schematic diagram of the octane rating test BASF octane rating engine used for experiments is as shown in Figure 1. The BASF octane rating engine was made to run for 20 to 30 minutes to warm up. Speed was kept constant at $600 \mathrm{rpm}$ whilst the ignition timing was varied in the range of $4^{\circ} \mathrm{CA}$ BTDC to $18^{\circ} \mathrm{CA}$ BTDC, temperature and pressure values were obtained and compared with Kiva4 and Kiva3vr2. Gasoline BASF octane rating engine is a single cylinder spark ignition engine as shown below.

\subsection{Multi-Dimensional Modeling}

In this study, fluid flow simulation was carried out using the latest version of Los 
Table 3. Test Engine Parameters (Pent-roof) [9].

\begin{tabular}{cc}
\hline Description & Value \\
\hline Model & 100198 4-valve pent-roof \\
\hline Bore $[\mathrm{mm}]$ & 85 \\
Stroke $[\mathrm{mm}]$ & 1.15 \\
Squish [mm] & 147 \\
Connecting rod length [mm] & 1500 \\
Speed [rpm] & 360 \\
Thsect [degs] & 720 \\
Cafin [CAD] & -10 \\
ATDC [CAD] & $9.9000 \mathrm{e}+5$ \\
Presi (initial pressure) [Pa] & 293.15 \\
Tempi (initial temperature) [K] & 0.0186 \\
Tspmas (fuel mass flow rate) [g] & 346.5 \\
Calign (start of spark ignition) [CAD] & 5 \\
Calinj (start of fuel injection) [CAD] &
\end{tabular}

Table 4. Test Engine Parameters (BASF) [8].

\begin{tabular}{cc}
\hline Description & Value \\
\hline Model & 65 \\
bore $[\mathrm{mm}]$ & 100 \\
Stroke $[\mathrm{mm}]$ & 332 \\
Displacement $\left[\mathrm{cm}^{3}\right]$ & 0.6 \\
Maximum power at full load and $600 \mathrm{rpm}[\mathrm{kw}]$ & 400 \\
Maximum fuel consumption $[\mathrm{g} / \mathrm{h}]$ at $600 \mathrm{rpm}$ & 0.6 \\
Orifice diameter $[\mathrm{mm}]$ & 750 \\
Mixture heater $[\mathrm{w}]$ & $10: 1$ \\
Compression ratio & 600 \\
Speed [rpm] & 40 btdc to $180 \mathrm{btdc}$ \\
Ignition timings & Kistler 6051 B (error 1\%) \\
Pressure transducer & Kistler 6517 BCD \\
Spark plug &
\end{tabular}

Alamos National Laboratory (LANL) CFD code, KIVA-4. KIVA-4, a transient, three-dimensional, multiphase, and multi-component code for the analysis of chemically reacting flows with sprays has been under development at LANL for several years. The code uses an Arbitrary Lagrangian Eulerian (ALE) methodology on a staggered grid, and discretizes space using the finite-volume technique. The code uses an implicit time-advancement with the exception of the advective 




Figure 1. BASF octane rating engine-single cylinder [8].

terms that are cast in an explicit but second-order monotonicity-preserving manner. Also, the convection calculations can be sub-cycled in the desired regions to avoid restricting the time step due to Courant conditions [10]. Comparing to the earlier versions of the KIVA code, detailed evaporation model together with ability for modeling unstructured mesh were added to the KIVA-4 [11]. Kiva contains a folder kiva3d that has subroutines. The kinetic chemistry subroutine CHEM contains the chemical kinetic commands of the fuel used and sometimes it is replaced with other kinetic models [12]. To accomplish this, the user must supply an appropriate input data set, as required for each kinetic reaction. The data set is comprised of forward and backward pre-exponential factors, activation temperatures and temperature exponents, along with stoichiometric species coefficients on the left and right sides of the reaction and exponents of species concentration in both the forward and backward rates of the reaction. This is not always the case, however [13], Table 5 indicates suggested input values for using CHEM on the gasoline fuel, and its chemical equation.

The column in Table 5 contains Itape values for the basic hydrocarbon fuel appearing in the fuel library. $\mathrm{CF}$ is the forward pre-exponential factor, and the stoichiometric coefficients for the fuel, $\mathrm{O}_{2}, \mathrm{CO}_{2}$, and $\mathrm{H}_{2} \mathrm{O}$ are labeled $\mathrm{nl}, \mathrm{n} 2, \mathrm{n} 3$, and $\mathrm{n} 4$ respectively. The concentration exponents for the fuel and oxidizer are labeled AEf and AEo. (Negative values for AEf imply that the reaction rate increases as the fuel concentration decreases.) An effective activation energy $\mathrm{EF}=$ $30 \mathrm{kcal} / \mathrm{mole}$ is suggested, which is equivalent to about $1.5078 \times 10^{4}$ in KIVA input units when divided by the universal gas constant in kcal/mole degree Kelvin 
Table 5. Suggested input data for single step oxidation reaction [13] [14].

\begin{tabular}{cccccccc}
\hline Fuel & CF & n1 & n2 & n3 & n4 & AEf & AEo \\
\hline Gasoline & $4.6 \times 10^{11}$ & 4 & 49 & 32 & 34 & +0.25 & +1.50 \\
\hline
\end{tabular}

[14]. Equation (1) is a single-step oxidation reaction that was used as the mechanism. This was used to remedy computational time issue; it describes the dissociation of $4 \mathrm{~mol}$ of $\mathrm{C}_{8} \mathrm{H}_{17}$ into $32 \mathrm{~mol}$ of $\mathrm{CO}_{2}$ and $34 \mathrm{~mol}$ of $\mathrm{H}_{2} \mathrm{O}$.

Chemical equation

$$
4 \mathrm{C}_{8} \mathrm{H}_{17}+49 \mathrm{O}_{2} \rightarrow 32 \mathrm{CO}_{2}+34 \mathrm{H}_{2} \mathrm{O}
$$

\subsection{Unstructured Mesh Generation}

The Case A: Kiva4 package includes a basic grid generator, K3PREP that writes a file called itape17 conforming to the specifications of the engine [4] [15].

\section{Pre-processing}

A pre-processor is a program that processes its input data to produce output that is used as input to another program like a compiler; in this case K3PREP is that program. K3PREP is a pre-processor that generates the mesh for the given geometry in form of an output file called otape 17 and that given geometry comes from a file called IPREP file that needs to be built manually. An IPREP file is a file that contains all the necessary information to generate the geometry. The geometry is built following the description of the quantities on the input data file "IPREP" in the order in which they appear using the epilogue file found in the K3PREP directory [4] [16].

An IPREP file was used by other researchers to generate a structured mesh using kiva3vr2, the mesh is as shown below in Figure 2 .

The same IPREP file was used in kiv4 to produce an unstructured mesh. In order to accomplish this, there were a few modifications or changes that had to be made in order for the file to work in kiva4. Changes made to IPREP file are indicated in Table 6.

After all the modification is done, the file is now ready to be compiled by the program K3PREP. The IPREP file should be placed in the same folder as the executed K3PREP program. On the command line the program is run with the command./K3prep. After the program has finished running, otape17 and otape11 are generated.

\section{Itape17 to Kiva4grid Convertor}

The file otape17 is renamed to itape17 and otape11 to itape11. A convertor (convertor.f) for converting kiva3vr2 mesh files to kiva4 format is provided in the main directory. It is compiled by a fortran compiler and will convert itape 17 to kiva4grid [1]. itape17, itape11 and convertor.f are inserted in the folder created. On the command terminal change directory to the folder created and the command; G95-O convertor.exe convertor.f is run. Where g95 is the compiler and - $\mathrm{O}$ is the command to generate an exe file. Convertor.exe is produced 




Figure 2. Structured kiva3vr2 mesh [11].

Table 6. Modification of IPREP file in kiva4 compared to kiva3vr2.

\begin{tabular}{|c|c|c|}
\hline Modification/parameter & Kiva4 & Kiva3vr2 \\
\hline Always start with Title, & K3PREP/100198 4-valve & K3PREP/100198 4-valve \\
\hline $\begin{array}{l}\text { Align the engine configurations in } \\
\text { order, and make sure that each } \\
\text { Configuration quantity that follow }\end{array}$ & $\begin{array}{l}\text { Bore }- \\
\text { Stroke }\end{array}$ & Bore \\
\hline $\begin{array}{l}\text { is close and in line with each other, } \\
\text { the last letter and number in line } \\
\text { with the previous and next quantity. }\end{array}$ & configuration & $\begin{array}{l}\text { Squish } \\
\text { thsect }\end{array}$ \\
\hline Alignment & $\begin{array}{l}\text { wedgeflag } 00 \\
\text { translate } 44\end{array}$ & $\begin{array}{l}\text { wedgeflag } 00 \\
\text { translate } 44\end{array}$ \\
\hline $\begin{array}{l}\text { Reshape.f requires seven values } \\
\text { either } 0_{s} \text { or } 1_{s} \text {, set ifixed to } 0_{s}\end{array}$ & $\begin{array}{l}\text { nblk1, nblk2, index1 index } 2 \text {, } \\
\text { intrp, irelax and ifixed }\end{array}$ & $\begin{array}{l}\text { nblk1, nblk2, index1 index } 2 \text {, } \\
\text { intrp and irelax }\end{array}$ \\
\hline
\end{tabular}

in the same folder. In the same directory the exe file is run with the command./Convertor.exe and Kiva4grid will be generated. Below is the generated kiva4grid unstructured mesh in Figure 3.

After all the input files are edited and generated, kiva4 is run in the command terminal with the command: ./kiva4.

Case B: Kiva4 package includes a basic grid generator, K3PREP that writes a file itape17 conforming to the specification. In order to reduce computational time, a $45^{\circ}$ asymmetrical mesh was created based on the symmetry of the combustion chamber of the BASF octane rating engine-single cylinder as shown in Figure 4.

Figure 5 illustrates a summarized flow chart of generating the kiva4grid using an iprep file in k3prep and how to run kiva4.

\subsection{Unstructured Mesh Quality and Mesh Refinement in Ensight}

In computational solutions of partial differential equations, meshing is a discrete 


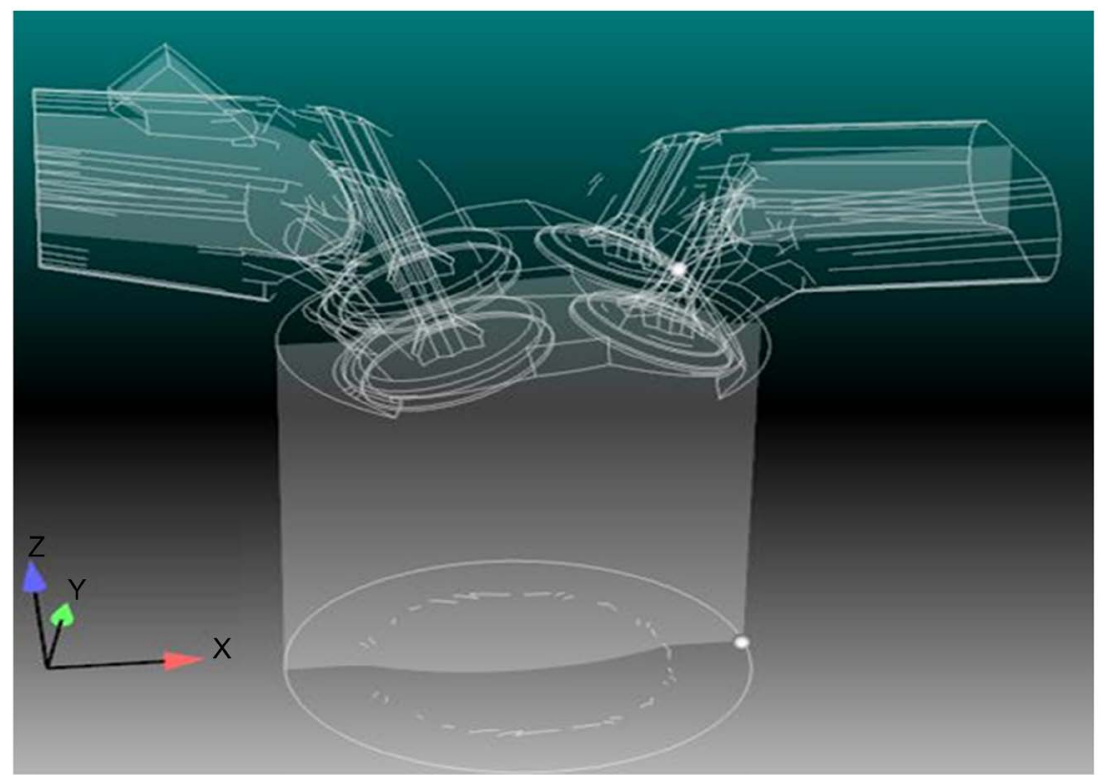

Figure 3. Kiva4grid Unstructured mesh.

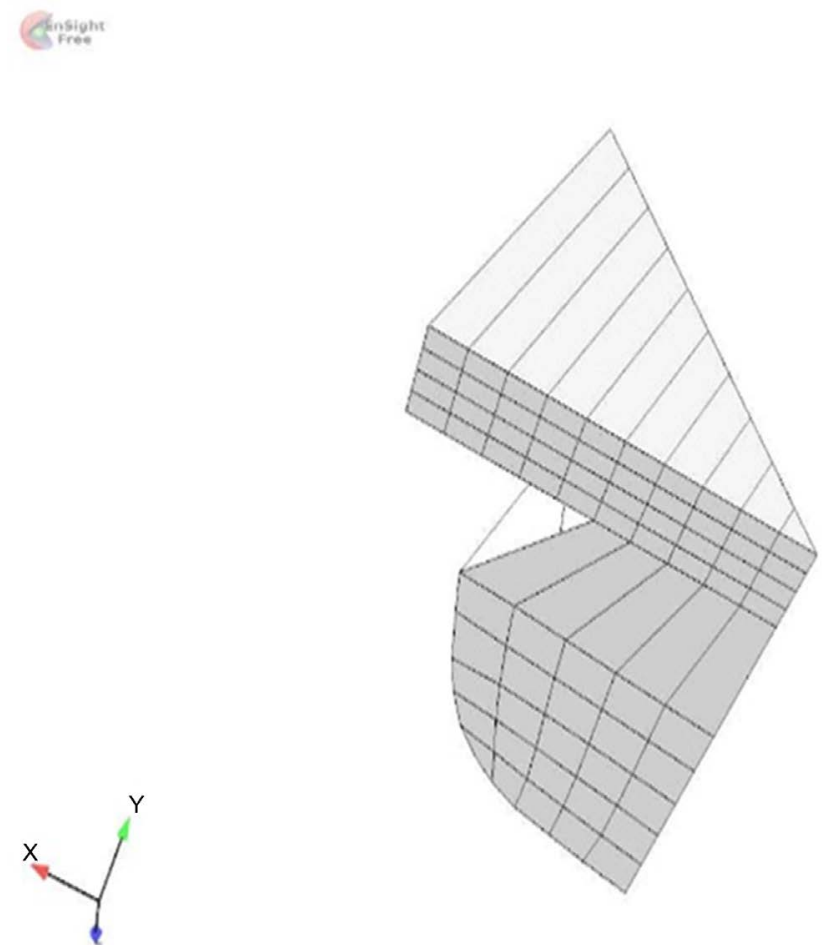

Figure $4.45^{\circ}$ asymmetrical sector of a BASF octane rating engine-single cylinder.

representation of the geometry that is involved in the problem. Essentially, it partitions space into elements (or cells or zones) over which the equations can be approximated. Zone boundaries can be free to create computationally best shaped zones, or they can be fixed to represent internal or external boundaries within a model. The mesh quality can be conclusively determined based on the following factor [17]. 


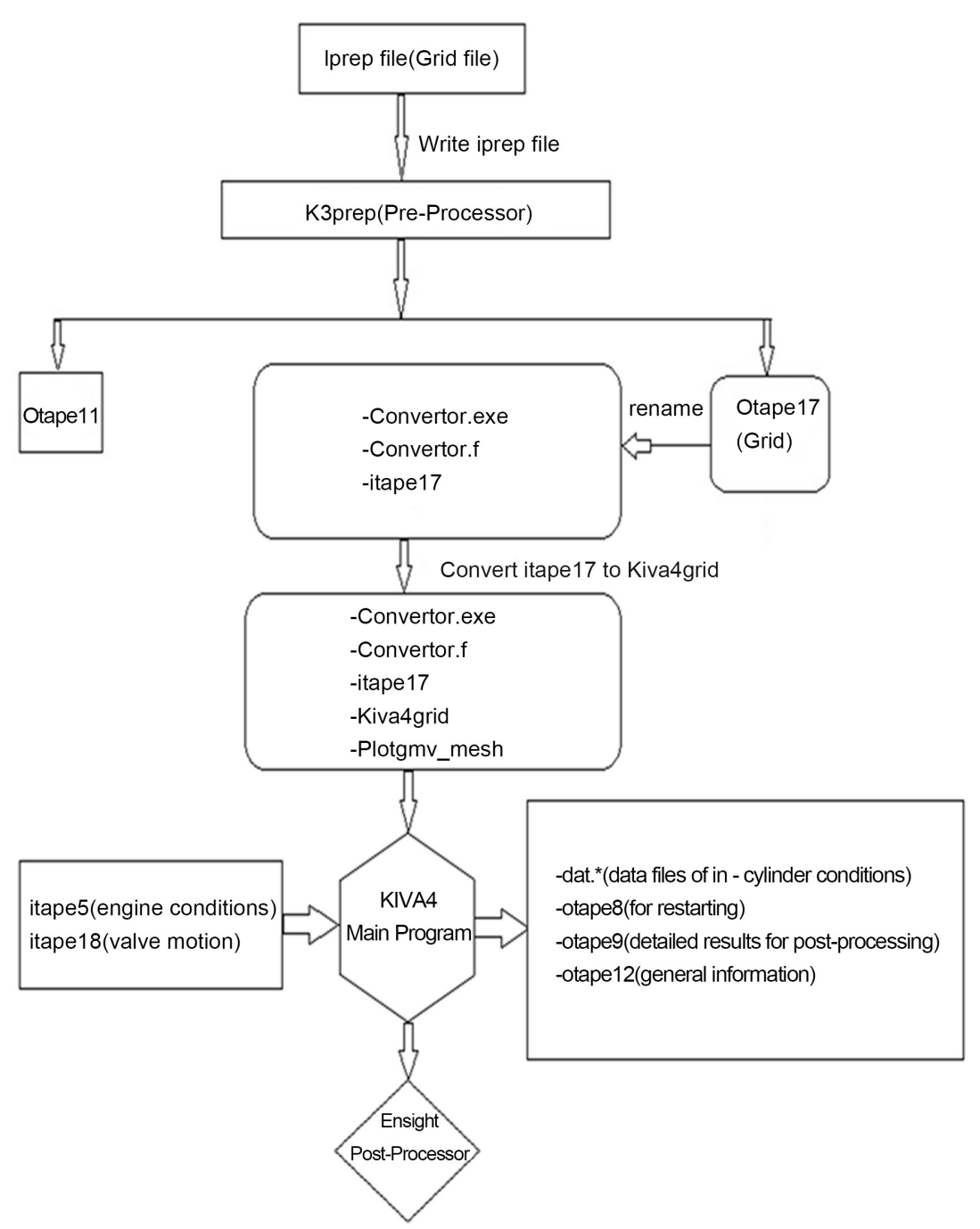

Figure 5. Summarized flow chart of generating mesh and running kiva4.

\section{Solution precision}

A better mesh quality provides a more precise solution. For example, one can refine the mesh at certain areas of the geometry where the gradients are high, thus increasing the fidelity of solutions in the region. Also, this means that if a mesh is not sufficiently refined then the precision of the solution is more limited. Thus, mesh quality is dictated by the required precision [18].

\section{Viewing mesh refinement in Ensight}

Ensight is a software program for visualizing, analyzing, and communicating data from computer simulations and/or experiments. In numerical analysis, adaptive mesh refinement, or AMR, is a method of adapting the accuracy of a solution within certain sensitive or turbulent regions of simulation, dynamically and during the time the solution is being calculated [18].

\section{Procedure}

To view mesh refinement, the global attribute is turned on and the color set to black. Available parts are hidden in order to view the mesh in the fluid domain. 
The fluid domain is clipped and the times set to a value were the mesh refinement is able to be viewed.

\section{Quantifying the size of the elements}

Element size calculates variables such as the volume/Area/Length for $3 \mathrm{D} / 2 \mathrm{D} / 1 \mathrm{D}$ elements respectively at each element creating a scalar, element-based variable.

\section{Procedure}

The option for calculator is selected in the fluid domain on the tabs. Elesize (element size) is searched on the calculator and evaluated for selected parts.

The clip is colored with elesize and the palette changed (set range to selected part $\max / \mathrm{min})$.

Figure 6 shows the results for quantifying the size of the elements in Ensight.

Figure 6 shows that the sizes of single elements are smaller in some parts of the geometry and larger in other parts. For the smaller cells elesize is 0.00013 while for the largest size elesize is 0.072 as shown.

There are many more ways and functions in Ensight that are designed to give the quantification of the grid. EleMetric is another function which calculates an elements mesh metric, at each element creating a scalar, element-based variable depending upon the selected metric function. Elemetric is searched on the calculator and other parameters called metric functions appear. In order to understand what each function does, the question mark is selected on the calculator which brings up the page for the user manual that explains what elemetric is, what each function does and what are the element types it applies to. Some of the examples of the elemetric functions are element type, facecount, centroid etc.

Gradient of the velocity

Gradient of the velocity is one of the physical quantities that the solver uses to

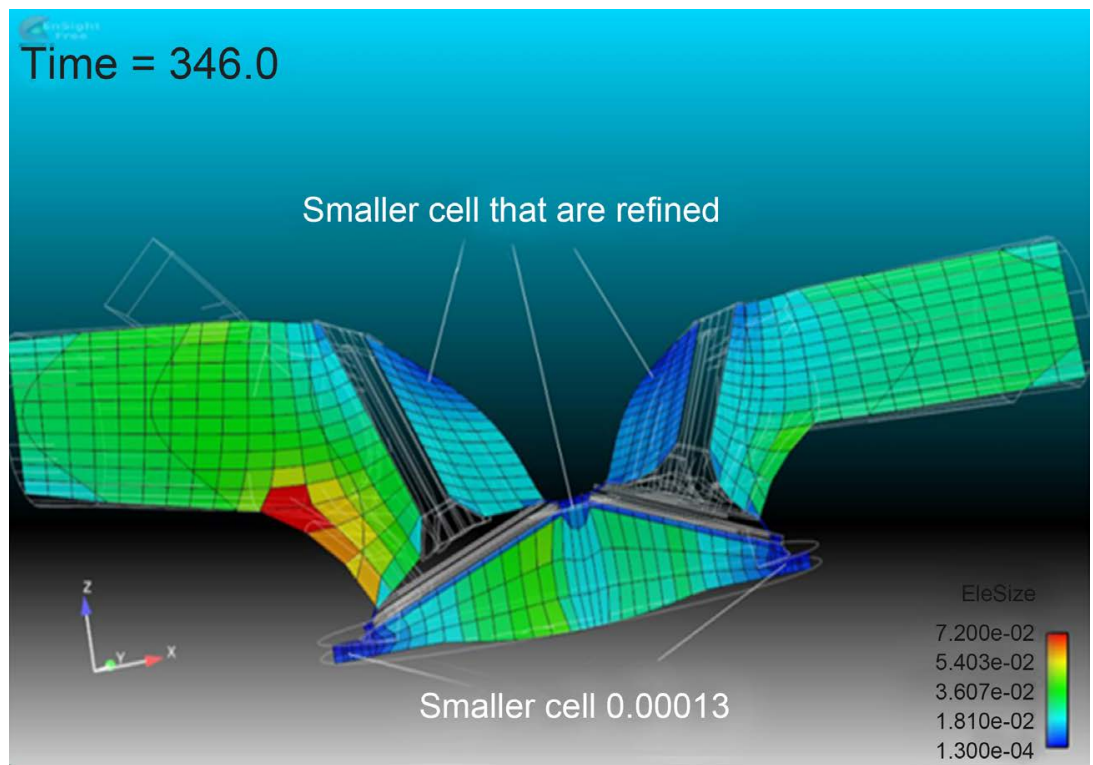

Figure 6. Quantifying the size of the elements in Ensight for the kiva4grid. (1.0e+6 dyne $/ \mathrm{cm}^{2}=1$ bar). 
identify which parts of the solution have to be refined. Gradient of the velocity is calculated. The designer selects the mesh configuration.

\section{Procedure}

The fluid domain is used when calculating the gradient of the quantity. The algorithm is used in each value of the cell and the true level of the neighboring cells to calculate the gradient. Selecting as a parent part 2D plane brings information that comes from the neighboring $2 \mathrm{D}$ cells but the solution in the solver used the 3D domain.

Grad is searched on the calculator. The scalar or vector velocity is selected and evaluated for selected parts. The clip plane is colored with GradV and the palate is edited in order to identify some features. The scale was set to logarithmic and the range was decreased from zero until it gave the required results as shown below in Figure 7.

Figure 7 shows that the solver has followed the areas where the gradient of the velocity is higher and refined those cells. The value for the highest gradient of the velocity is 1202 .

\section{Results and Discussion}

Figure 8 shows the Intake stroke which starts with the piston at top dead center (TDC) and ends with the piston at bottom dead center (BDC). Gasoline and air are drawn into the combustion chamber of the engine. As seen in the kiva4 results, the air is represented by the isosurface which is blue in color and the gasoline is sprayed red in color. The initial temperature in kiva4 and kiva3vr2 is $293.15 \mathrm{~K}$ and the initial pressure is $9.9000 \mathrm{e}+5 \mathrm{~Pa}$.

Figure 9(a) shows the power stroke. This is when the piston moves from top dead center to bottom dead center. Here pressure increases rapidly causing an



Figure 7. Gradient of the velocity in Ensight for the kiva4grid $\left(1.0 \mathrm{e}+6 \mathrm{dyne} / \mathrm{cm}^{2}=1 \mathrm{bar}\right)$. 


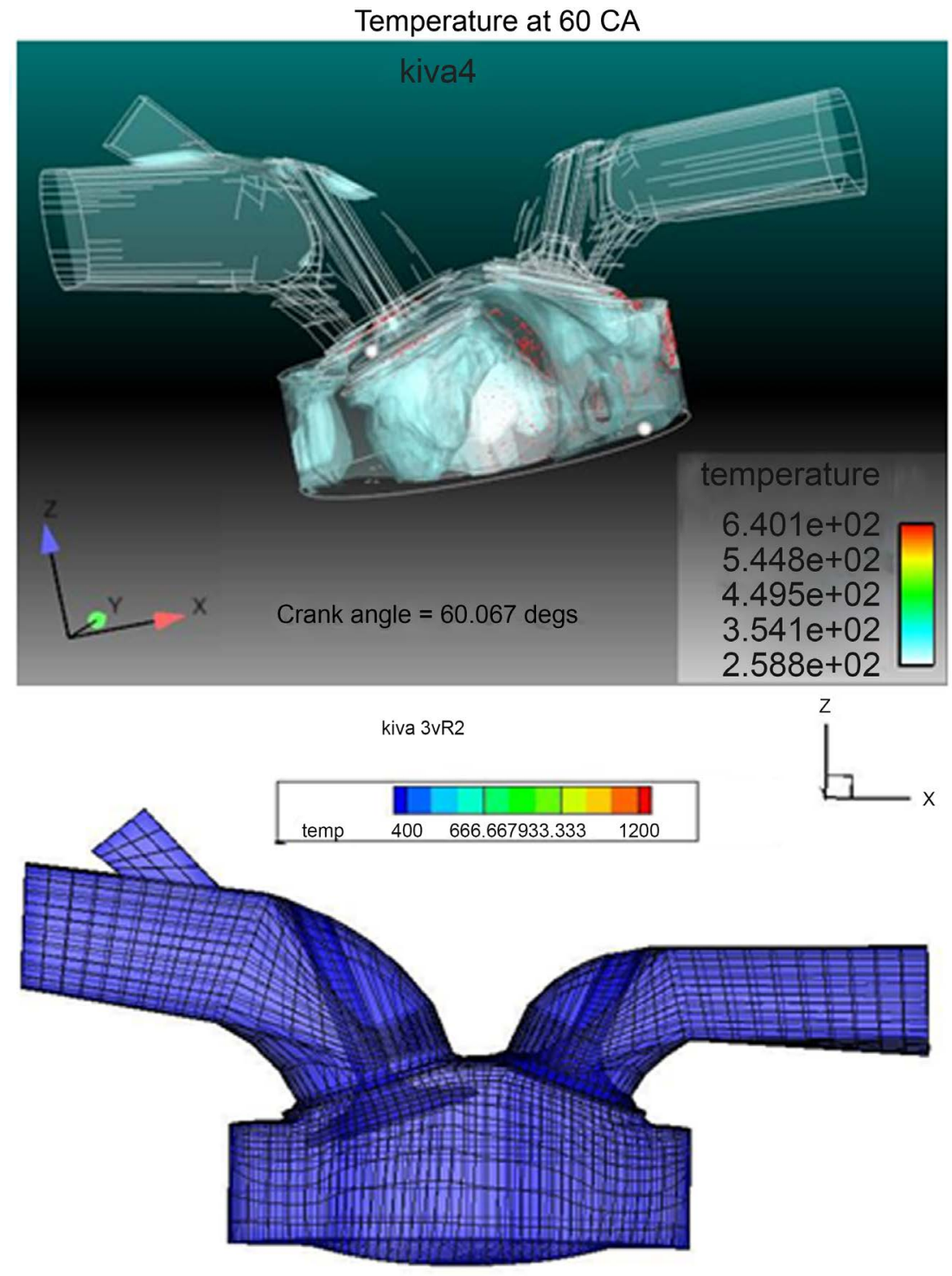

Temperature Countour at CA-60

Figure 8. Temperature profiles for Kiva4 and kiva3vr2 at $60 \mathrm{CA}$. Intake stroke (1.0e+6 dyne $/ \mathrm{cm}^{2}=1$ bar).

increase in temperature. The average temperature and pressure for kiva4 is 640 $\mathrm{K}$ and 16.48 bars while that for kiva3vr2 is $600 \mathrm{~K}$ and 14.83 bars. Combustion takes place when ignition occurs at $346.5 \mathrm{CA}$ causing the piston to move from top dead center to bottom dead center. As seen from kiva4 graphs, both the isosurface and clipboard are completely red indicating high pressure and temperature. The average pressure before combustion in kiva4 shows 16.48 bars.

Figure 9(b) shows the piston moving from top dead center to bottom dead center. Power or work is generated by the rapid heat generated in the combustion chamber. The temperature generated in Kiva4 is $1940 \mathrm{~K}$ while in Kiva3vr2 is $1819 \mathrm{~K}$ at $370 \mathrm{CA}$. The pressure generated in Kiva4 is 19.4 bars while in Kiva3vr2 
is 17.46 bars at $360 \mathrm{CA}$. Temperature and pressure continues to slightly increase then it reduces due to heat losses.

Figure 10 shows the exhaust stroke. The piston moves from bottom dead center to top dead center when the intake valves are closed while the exhaust valves are open to allow the emissions to be released to the environment. The temperature and pressure has reduced to $483 \mathrm{~K}$ and 1.01 bars in Kiva4 while in Kiva3vr2 $453 \mathrm{~K}$ and 0.91 bars at $540 \mathrm{CA}$. This can also be seen from the results in the simulation that it has gone back to green then blue. The simulation is then terminated at $720 \mathrm{CA}$.

\subsection{Comparing Experimental Results with Kiva4 and Kiva3vr2}

A comparison is made in this section between the measured values derived from the experimental investigation and the ones calculated by kiva4 and kiva3vr2. Figure 11 shows the pressure-crank angle diagram.

Combustion is a process formed when there is a source of fuel, air (oxidizer) and heat [19]. This is the most important process taking place in spark ignition engines in which chemical energy of the fuel is transformed into internal energy of the cylinder charge. During this process, a turbulent flame propagates across


(a) 
Temperature at $370 \mathrm{CA}$
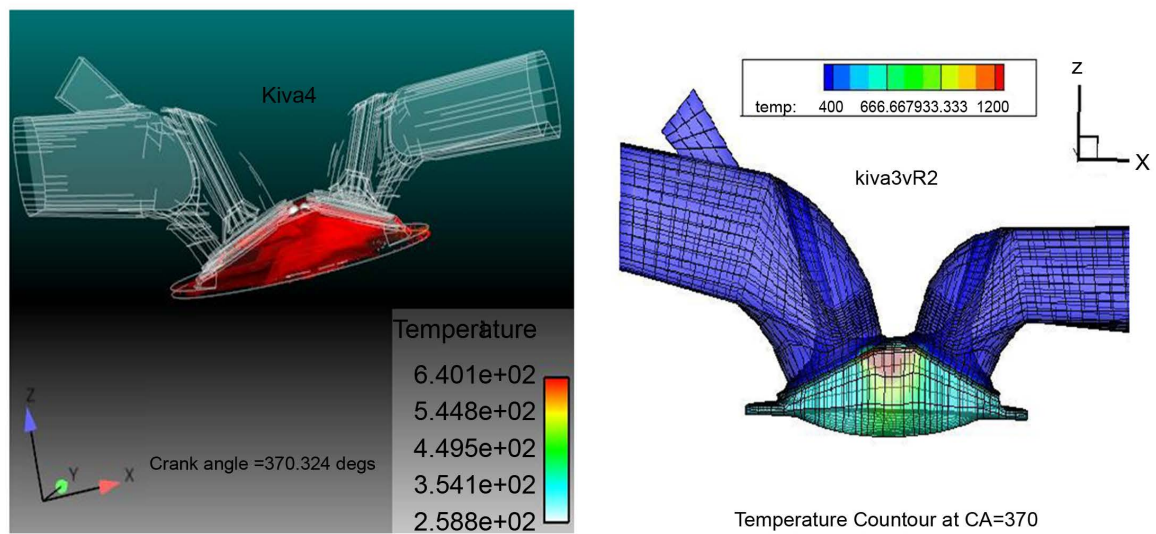

Temperature Countour at $\mathrm{CA}=370$

Pressure at $360 \mathrm{CA}$
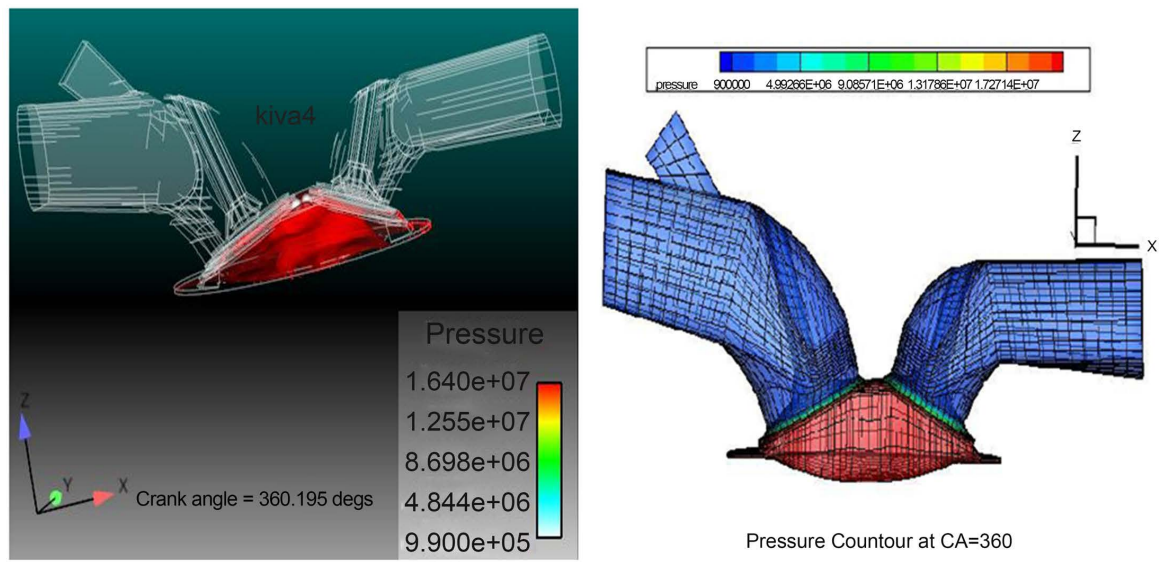

Pressure Countour at $\mathrm{CA}=360$

(b)

Figure 9. (a) Temperature and pressure profiles for Kiva4 and kiva3vr2 at 345 CA. Expansion stroke $\left(1.0 \mathrm{e}+6 \mathrm{dyne} / \mathrm{cm}^{2}=1 \mathrm{bar}\right)$; (b) Temperature and pressure profiles for Kiva4 and kiva3vr2 at $345 \mathrm{CA}$. Expansion Stroke $\left(1.0 \mathrm{e}+6 \mathrm{dyne} / \mathrm{cm}^{2}=1 \mathrm{bar}\right)$.

\section{Temperature at $540 \mathrm{CA}$}

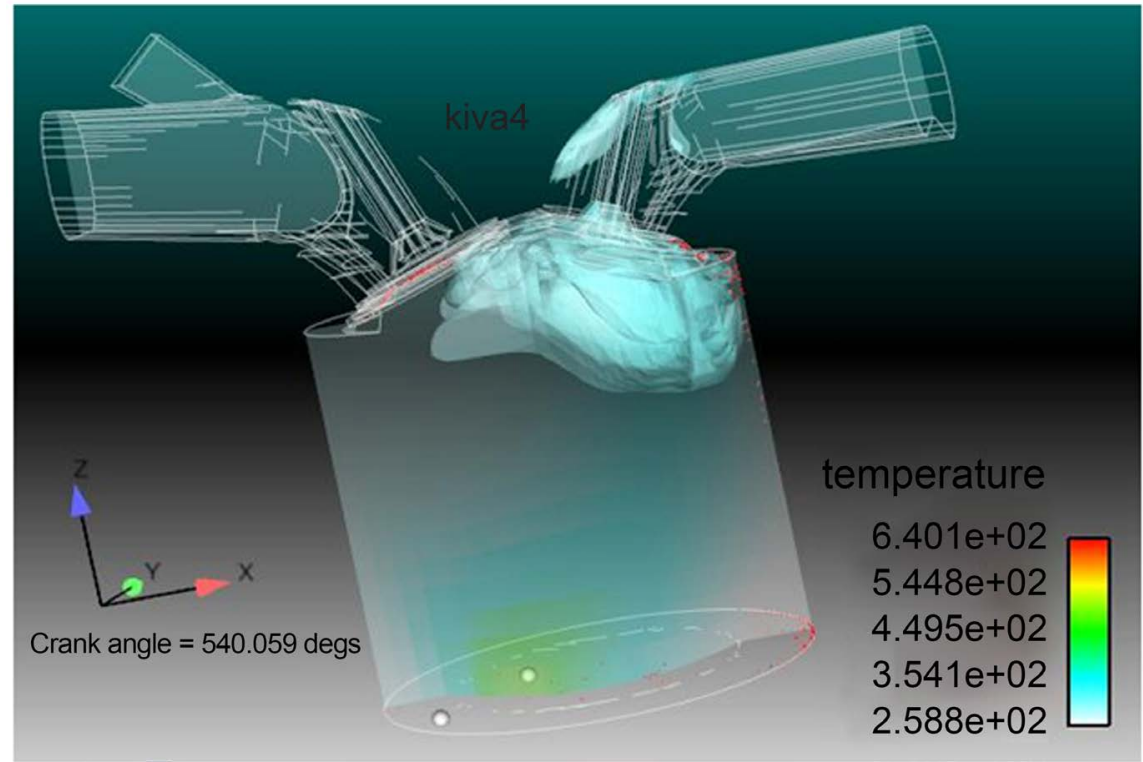






Figure 10. Temperature profiles kiva4 and kiva3vr2 at 540 CA. Exhaust Stroke (1.0e+6 dyne $/ \mathrm{cm}^{2}=1$ bar).

the combustion chamber and burns the premixed gasoline-air mixture. The fuel is injected at $5^{\circ}$ ATDC during the intake stroke when the piston is moving from top dead center to bottom dead center. The piston moves from bottom dead center to top dead center. The air-fuel mixture is compressed isentropically through the compression ratio, in this case 10:1. Heat is added to the working fluid during compression process at constant volume. The temperature and pressure slowly increases as the piston moves from bottom dead center to top dead center. Combustion occurs when the temperature and pressure of the air-fuel mixture is high enough to ignite at $4^{\circ} \mathrm{CA}, 8^{\circ} \mathrm{CA}, 10^{\circ} \mathrm{CA}$ and $18^{\circ} \mathrm{CA}$ before top dead center. This is called the ignition phase at $356^{\circ} \mathrm{CA}$ as seen from Figures 11(a)-(d). When combustion takes place, the piston moves from TDC to BDC with a greater amount of force and work is done by the system. The peak temperature is above $2000 \mathrm{~K}$ and the peak pressure is above 20 bars. Kva4 results are closer to the experiment than kiva3vr2. Figures 11(a)-(d) shows a variation of pressure with time during the combustion of gasoline-air mixture where the pressure is in bars and the time is in crank angle degrees [CAD]. The initial pressure Presi and temperature Tempi are 1.929802218e+6 Pa and $400 \mathrm{~K}$. The calculations begin at $60 \mathrm{degs}$ btdc and finishes at 540 degs atdc. The simulation results in kiva4 agree with the experimental results. The average pressure is 19.56 bars in kiva4 and 18.2115 bars in kiva3vr2 while for the experiment the pressure is 18.8756 bar. Kiva3vr2 generates slightly lower pressure results than Kiva4 due to the changes made in kiva4.

\subsection{Combustion Characteristics}

After testing Kiva4's performance and accuracy, simulations are performed based 

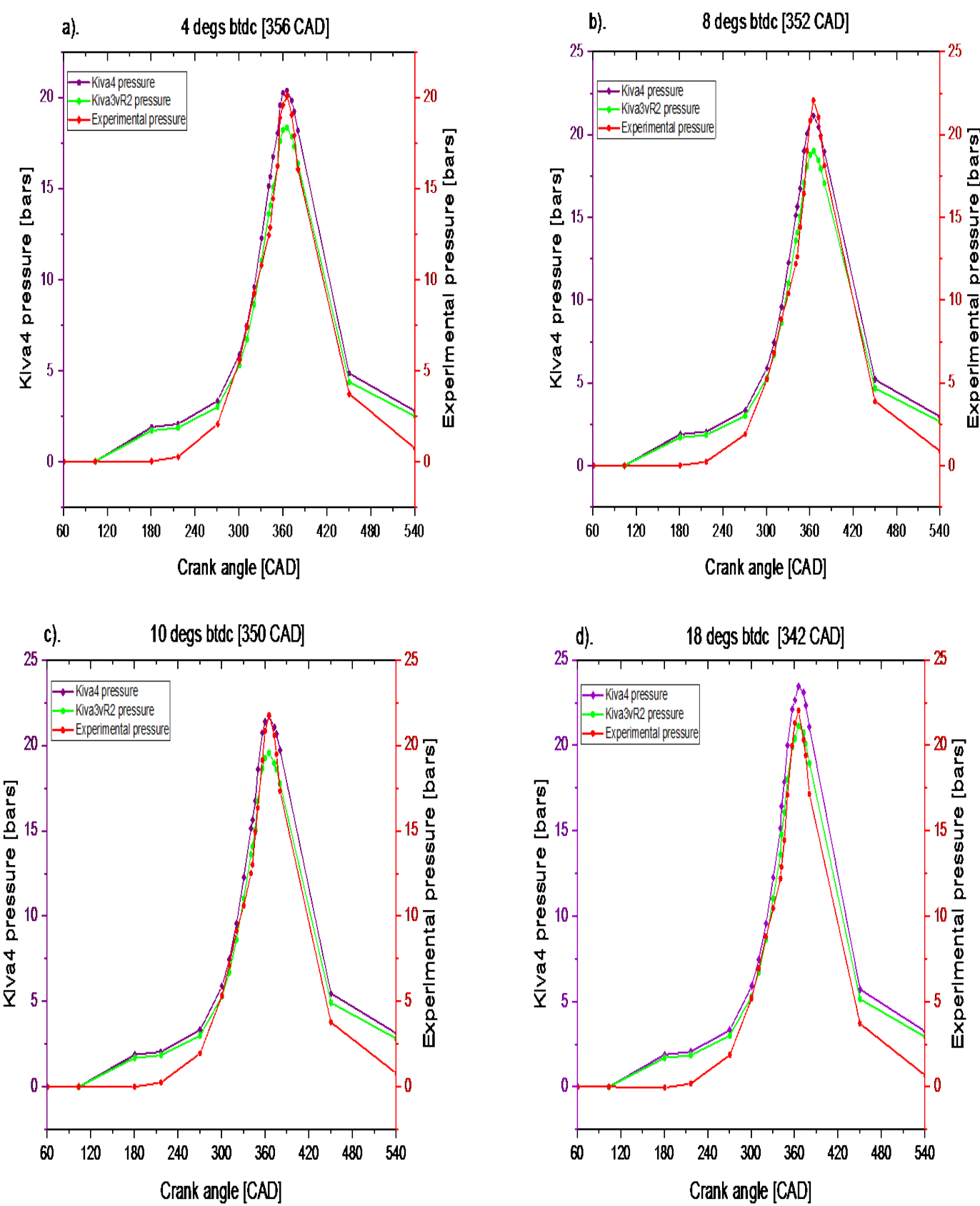

Figure 11. Comparing pressure data from Kiva4 and kiva3vr2 results with experimental data under varying ignition timing conditions at $600 \mathrm{rpm}$.

on the input parameters of the experimental cases for the ignition timing of $4^{\circ}$ $\mathrm{CA}, 8^{\circ} \mathrm{CA}, 10^{\circ} \mathrm{CA}$ and $18^{\circ} \mathrm{CA} \mathrm{BTDC}$ at $600 \mathrm{rpm}$. When the calculations begin at 60 degs BTDC, the response of the pressure and temperature is slow and uniform. During the compression stroke at $180 \mathrm{CAD}$ the pressure and temperature in the cylinder begins to build up until it is high enough for combustion to occur. The ignition timing in crank angle degrees (CAD) is (a) 356 CAD, (b) 352 CAD, (c) $350 \mathrm{CAD}$ and (d) $342 \mathrm{CAD}$ as shown in Figure 12. Table 7 indicates the initial conditions used in kiva4. 


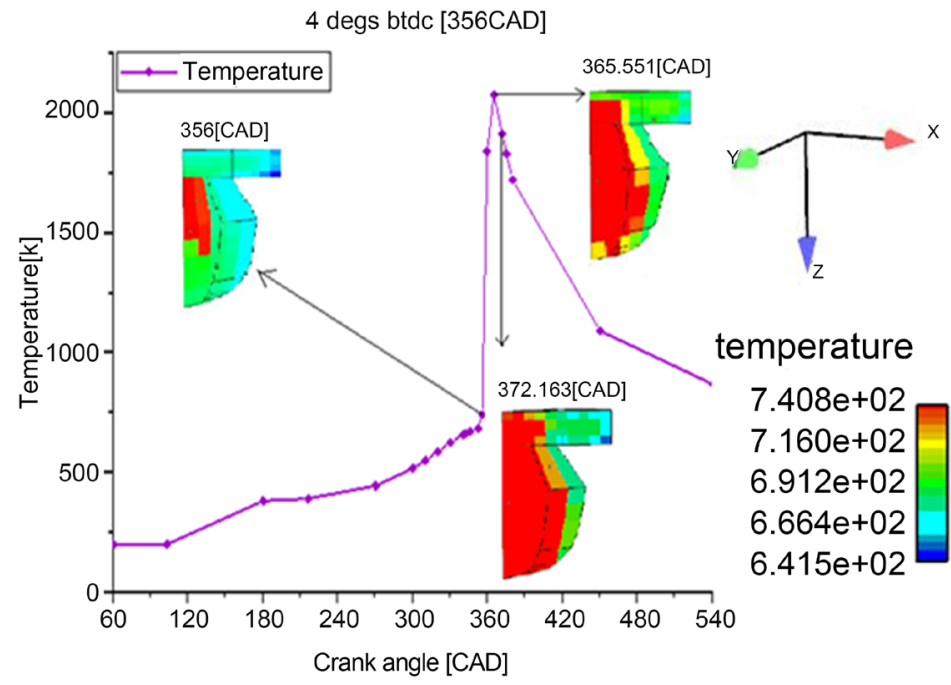

(a)

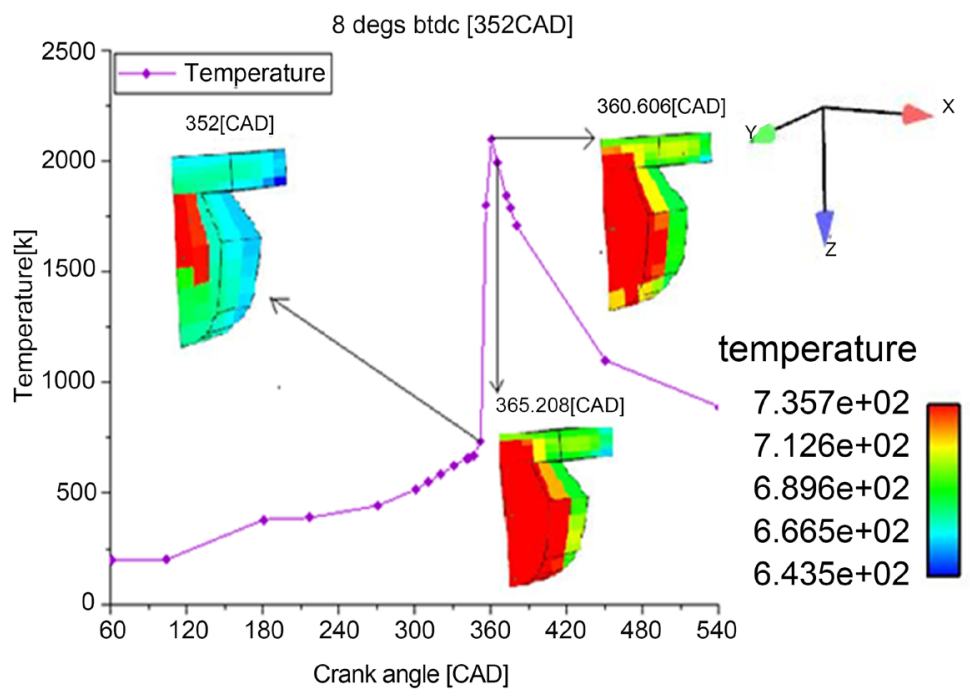

(b)

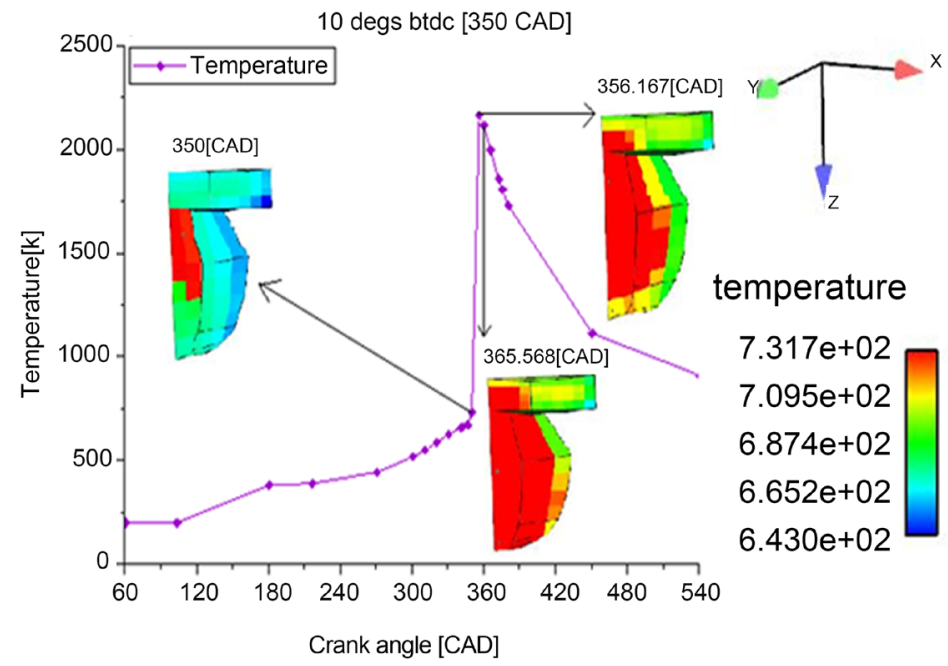

(c) 


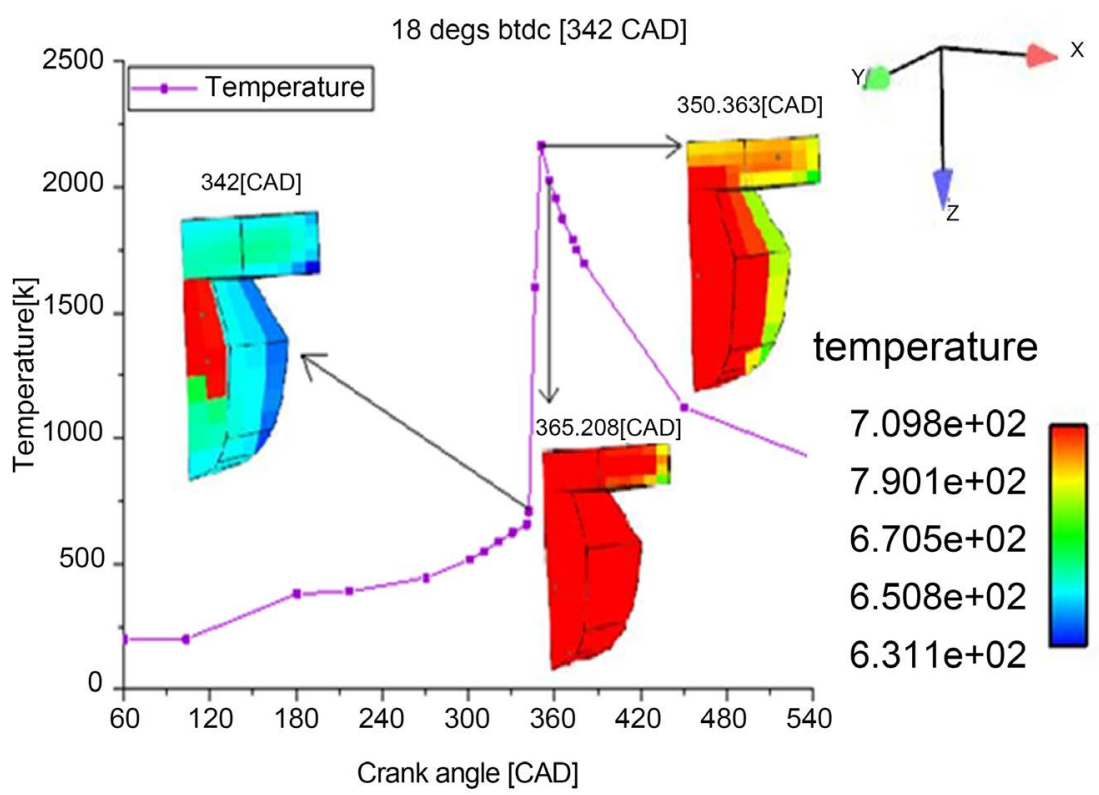

(d)

Figure 12. Temperature simulation results in kiva4 at (a) 4 degs btdc and (b) 8 degs btdc at $600 \mathrm{rpm}$; Temperature simulation results in kiva4 at (c) 10 degs btdc and (d) 18 degs btdc at $600 \mathrm{rpm}$.

Table 7. Kiva4 initial conditions.

\begin{tabular}{cc}
\hline Parameters & Values \\
\hline Presi (initial pressure) $[\mathrm{Pa}]$ & $1.929802218 \mathrm{e}+6$ \\
Tempi (initial temperature) $[\mathrm{K}]$ & 400.0 \\
Tspmas (fuel mass flow rate) $[\mathrm{g}]$ & 0.0116 \\
calign (start of spark ignition) [CAD] & $356.0,352.0,350.0$ and 342.0 \\
calinj (start of fuel injection) [degs] & $5.0^{\circ} \mathrm{btdc}$ \\
\hline
\end{tabular}

When Combustion occurs, the volume of the burned gasoline - air mixture expands. The expansion of the burning mixture starts at the center and travels in the outward direction towards the cylindrical vessel wall. This movement created a combustion wave that causes a rise in pressure (Lewis \& Elbe, 1987) [20]. However, as the combustion process passes over $350 \mathrm{CAD}$, the pressure and temperature starts to increase exponentially until it reaches its peak pressure and temperature. The average temperature and pressure decreases while the peak temperature and pressure increases as shown in Figure 12 (a) 20.37 bars, $2075.7 \mathrm{~K}$, (b) 21.13 bars $2101.5 \mathrm{~K}$, (c) 21.71 bars, $2163.8 \mathrm{~K}$ and (d) 23.47 bars, $2166.0 \mathrm{~K}$ for the ignition timing $4^{\circ} \mathrm{CA}, 8^{\circ} \mathrm{CA}, 10^{\circ} \mathrm{CA}$ and $18^{\circ} \mathrm{CA}$ respectively. As the combustion wave propagates and echoed back once it hit the cylinder wall, the rapid movement interacts with the burning flame front. The small disturbance over the flame front increases the rate of combustion in a way that the unburned mixture is compressed towards the flame front. 


\subsection{Effect of Ignition Timing on Temperature and Pressure}

The results show that increasing spark advance increases the peak temperature and peak pressure in the combustion chamber. Figure 13 and Figure 14 show how temperature and pressure increases with increase in spark advance. Best performance will be achieved when the greatest portion of the combustion takes place near top dead center. If the spark is not advanced enough, the piston will already be moving down when much of the combustion takes place. In this case, we lose the ability to expand this portion of the gas through the full range, decreasing performance. If ignition is too advanced, too much of the gas will burn while the piston is still rising. As a result, the work that must be done to compress this gas will decrease the total work produced [6] [21]. Figure 13 and Figure 14 show the peak temperature and pressure at different ignition time. It is expected that peak temperature and pressure should increase, thereby increasing power and torque. After peak temperature and pressure increases, it then drops off as the spark continues to advance further. Increasing the spark advance does not mean that the performance of an SI engine increases. An excessive increase in the ignition timing may result in detonation when using fuels with a low octane rating. The performance of an SI engine highly depends on ignition timing, and its optimum value should be determined for each SI engine in order to achieve higher combustion efficiency. The peak temperatures at $4^{\circ} \mathrm{CA}, 8^{\circ} \mathrm{CA}$, $10^{\circ} \mathrm{CA}$ and $18^{\circ} \mathrm{CA}$ BTDC are $2075.7 \mathrm{~K}, 2101.5 \mathrm{~K}, 2163.8 \mathrm{~K}$ and $2166.0 \mathrm{~K}$ respectively. The peak pressures at of $4^{\circ} \mathrm{CA}, 8^{\circ} \mathrm{CA}, 10^{\circ} \mathrm{CA}$ and $18^{\circ} \mathrm{CA} \mathrm{BTDC}$ are 20.37 bars, 21.13 bars, 21.73 bars and 23.47 bars respectively.

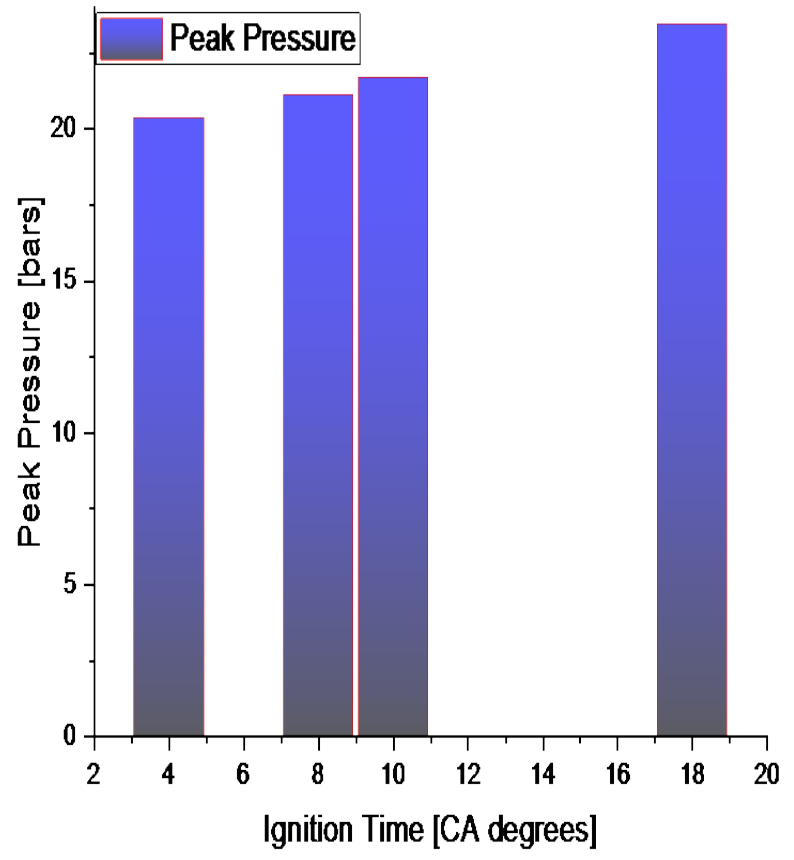

(a)

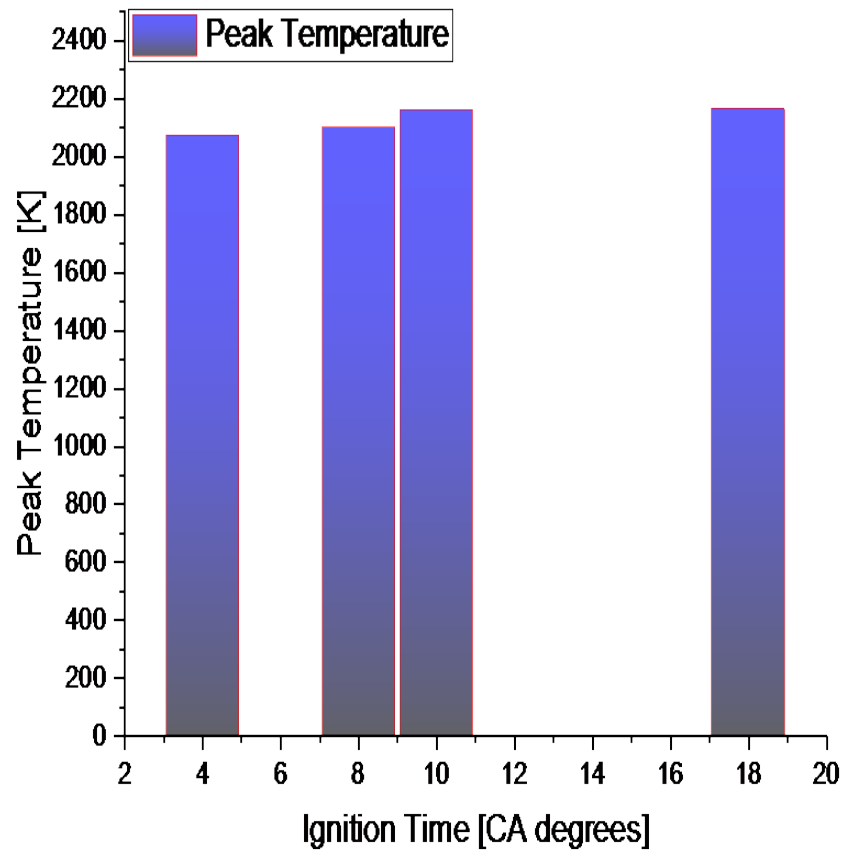

(b)

Figure 13. (a) Peak Pressure and (b) Temperature under different ignition timing. 
AVERAGE PRESSURE
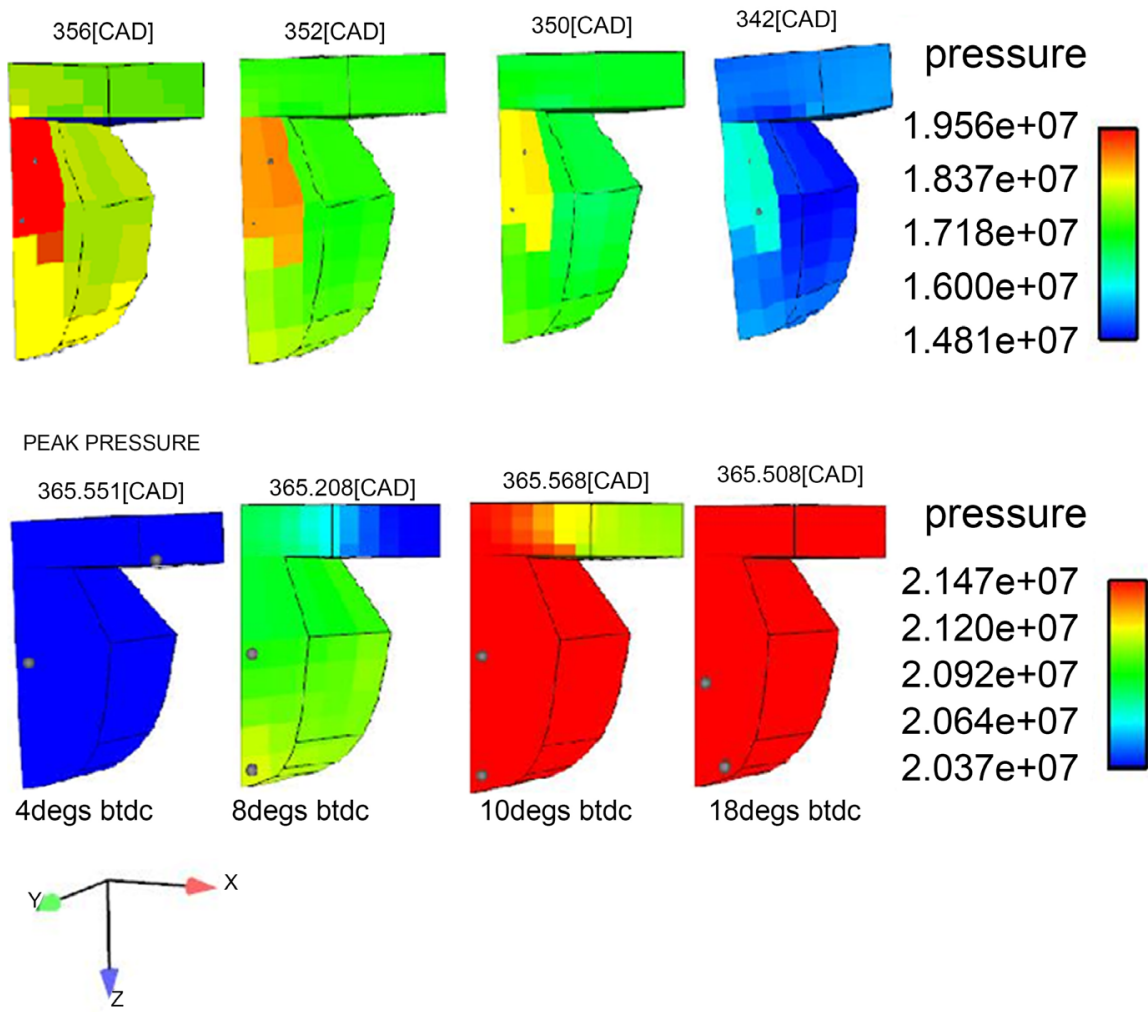

pressure

$2.147 \mathrm{e}+07$

$2.120 \mathrm{e}+07$

$2.092 \mathrm{e}+07$

$2.064 \mathrm{e}+07$

$2.037 \mathrm{e}+07$

Figure 14. Average pressure and Peak pressure kiva4 simulation results for $4^{\circ} \mathrm{CA}, 8^{\circ} \mathrm{CA}$, $10^{\circ} \mathrm{CA}$ and $18^{\circ} \mathrm{CA}\left(1.0 \mathrm{e}+6 \mathrm{dyne} / \mathrm{cm}^{2}=1 \mathrm{bar}\right)$.

\section{Conclusions}

The objective of this study was to show that kiva4 is more accurate than kiva3vr2 under different ignition timings. The numerical accuracy of kiva4 was compared with the numerical results obtained by other researchers who used kiva3vr2 as the simulation code. The combustion characteristics of gasoline under different ignition timings are obtained using kiva4 and the following conclusions are drawn.

1) After mesh refinement, very fine meshes were obtained with Kiva4 with the highest gradient of 1202 thus had increased fidelity of solutions in the regions.

2) An unstructured mesh was used in Kiva 4 and a structured mesh in Kiva3vr2. More accurate results were obtained in Kiva4 than in Kiva3vr2. The average temperature and pressure in kiva4 were $640 \mathrm{~K}$ and 16.48 bars while in kiva3vr2 were $600 \mathrm{~K}$ and 14.83 bars, the peak temperature and pressure in kiva4 were $2316.3 \mathrm{~K}$ and 21.5 bars while in kiva3vr2 were $2171.5 \mathrm{~K}$ and 19.4 bars.

3) Peak temperature and pressure increase with late timing of the spark before top dead center. The peak temperature and pressure increase with increasing spark advance until the most favorable instant time is determined. Best performance was achieved when the ignition time was set to 10 degrees before top dead center. 


\section{Conflicts of Interest}

The authors declare no conflicts of interest regarding the publication of this paper.

\section{References}

[1] Torres, D.J. (2006) KIVA-4 Manual Los Alamos Natl. Lab. Theoretica 1-13.

[2] Imamori, Y., Hiraoka, K., Murakami, S., Endo, H., Rutland, C.J. and Reitz, R.D. (2009) Effect of Mesh Structure in the KIVA-4 Code with a Less Mesh Dependent Spray Model for DI Diesel Engine Simulations. SAE International Journal of Engines, 2, 1764-1776. https://doi.org/10.4271/2009-01-1937

[3] Ng, E. (2011) Implementation of the Conjugate Heat Transfer Code in Masters Report, Michigan Technol. Univ. 11-6.

[4] Amsden T-3 (1997) KIVA-3V, Release 2, Improvements to KIVA-3V LAMS Report, Los Alamos Natl. Lab. 836 0-34.

[5] Torres, D.J. and O’Rourke, D.P.J. (1997) Unstructured KIVA Int. Multidimens. Engine Model. Users Fluid Dyna 0-6.

[6] Kakaee, A.H., Shojaeefard, M.H. and Zareei, J. (2011) Sensitivity and Effect of Ignition Timing on the Performance of a Spark Ignition Engine: An Experimental and Modeling Study. Journal of Combustion, 2011, Article ID 678719. https://doi.org/10.1155/2011/678719

[7] Priyadarsini, I., Priyadarsini, I., Krishna, M.V.S.M. and Devi, E.N. (2015) Study of Impact of Spark Timing and Compression Ratio on Performance of SI Engine. Research Gate, 1-32.

[8] Siwale, L.Z., Kolesnikov, P.A., Bereczky, P.A. and Mbarawa, M. (2012) Effect of Oxygenated Additives in Conventional Fuels for Reciprocating Internal Combustion Engines on Performance Combustion and Emission Characteristics. P.H.D. Thesis, Tshwane Univ. Technol., Pretoria.

[9] Chen, Y., Yang, S.-L. and Predebon, W.W. (2011) Simulation of Four Stroke Engine Cycle for a 4-Valve Pentroof Engine in KIVA 3VR2. Masters Report, Digital Commons@ Michigan Technol. Univ.

[10] Aytulu, D. (2016) KIVA-Hydrodynamics Model for Chemically Reacting Flow with Spray. Lab. Los Alamos Natl. 4/12.

[11] Maghbouli, A., Yang, W., An, H., Li, J., Chou, S.K. and Chua, K.J. (2013) An Advanced Combustion Model Coupled with Detailed Chemical Reaction Mechanism for D.I Diesel Engine Simulation. Applied Energy, 111, 758-770. https://doi.org/10.1016/j.apenergy.2013.05.031

[12] Amsden, A.A. (1997) KIVA-3V: A Block-Structured KIVA Program for Engines with Vertical or Canted Valves LA Rep. LA-13313-MS.

[13] Amsden, A.A., O’Rourke, P.J. and Butler, T.D. (1989) KIVA-II: A Computer Program for Chemically Reactive Flows with Sprays.

[14] Amsden, A.A. (1993) KIVA-3: A KIVA Program with Block-Structured Mesh for Complex Geometries.

[15] Engine Research Center (2000) K3PREP Workshop What Is K3PREP \& Sample Grid. University of Wisconsin-Madison, Madison, 1-43.

[16] Donea, J., Huerta, A., Ponthot, J. and Rodr, A. (1999) Arbitrary Lagrangian-Eulerian Methods. Encyclopedia of Computational Mechanics, 1-25.

[17] Bern, M. and Plassmann, P. (1999) Mesh Generation Subjects Inhandb. Elsevier, 
Amsterdam, 291-332.

[18] Berger, M.J. and Colella, P. (1989) Local Adaptive Mesh Refinement for Shock Hydrodynamics. Journal of Computational Physics, 82, 64-84.

[19] Aznam, S.N.A. (2015) Combustion Visualization and Measurement in a Closd Vessel. PHD Thesis, University of Technology, Malaysia, 1-20.

[20] Aznam, S.N.A. and Saat, A. (2016) Pressure Rise Generation by the Combustion of Methane-Air in a Closed Vessel. ARPN Journal of Engineering and Applied Sciences, 11, 5146-5149.

[21] Tunka, L. and Polcar, A. (2017) Effect of Various Ignition Timings on Combustion Process and Performance of Gasoline Engine. Acta Universitatis Agriculturae et Silviculturae Mendelianae Brunensis, 65, 545-554.

https://doi.org/10.11118/actaun201765020545

\section{Nomenclature}

MFB: Mass Fuel Burned (\%)

BTDC: Before Top Dead Centre

BDC: Bottom dead center

TDC: Top Dead Centre

CAD: Crank Angle Degrees

CR: Compression Ratio

LHV: Lower heating value $(\mathrm{MJ} / \mathrm{kg})$

IMEP: Indicated Mean Effective Pressure (bars)

FID: Flame Ionization Detection

CA: Crank Angle

EOC: End of Combustion

IBP: Initial Boiling Point

RVP: Absolute vapor pressure $(\mathrm{kPa}, \mathrm{psi}$ ) measured above liquid petroleum products at $37.8^{\circ} \mathrm{C}$ by Reid method determined by ASTM D323

VP: Vapor pressure

$\lambda$ : ratio of actual air-to-fuel-ratio to stoichiometric air-to-fuel ratio

ECU: Electronic control unit

SI: Spark Ignition 